ORIGINAL ARTICLE

\title{
An evaluation of mouthguard requirements and dental injuries in New Zealand rugby union
}

\author{
K L Quarrie, S M Gianotti, D J Chalmers, W G Hopkins
}

Br J Sports Med 2005;39:650-654. doi: 10.1136/bjsm.2004.016022

See end of article for authors' affiliations

Correspondence to: Mr Quarrie, NZ Rugby Football Union, Research and Injury Prevention, PO Box 2172 , Wellington, New Zealand; ken.quarrie@nzrugby. co.nz

Accepted 23 January 2005

\begin{abstract}
Objectives: To document the effects of compulsory mouthguard wearing on rugby related dental injury claims made to ACC, the administrator of New Zealand's accident compensation scheme.

Methods: An ecological study was conducted. Estimates of mouthguard wearing rates were available from prospective studies conducted in 1993, 2002, and 2003. Rugby related dental injury claims were available for the period 1995-2003. Player numbers were available from 1998. Mouthguard wearing was made compulsory during match play for rugby players at under 19 level and below at the beginning of the 1997 season, and for all grades of domestic rugby at the beginning of the 1998 season. Greater powers of enforcement were provided to referees at the beginning of the 2003 season.

Results: The self reported rate of mouthguard use was $67 \%$ of player-weeks in 1993 and $93 \%$ in 2003. A total of 2644 claims was reported in 1995. There was a $43 \%$ (90\% confidence interval $39 \%$ to $46 \%$ ) reduction in dental claims from 1995 to 2003 . On the reasonable assumption that the number of players and player-matches remained constant throughout the study period, the relative rate of injury claims for non-wearers versus wearers was $4.6(90 \%$ confidence interval 3.8 to 5.6$)$. The cumulative savings in claim costs compared with the cost per year if claim numbers had remained constant from 1995 is $\$ 1.87$ million NZD.

Conclusion: Although ecological studies have acknowledged weaknesses, the findings provide evidence that mouthguard use is a simple and effective injury prevention strategy for rugby players. The use of mouthguards for all players in both matches and contact practice situations is strongly recommended.
\end{abstract}

$\mathrm{R}$ ugby union is a widely played physical contact sport that enjoys particular popularity in the United Kingdom, France, South Africa, Australia, New Zealand, and some Pacific Island nations. Injuries are common, primarily because of the physical contact during tackles, rucks, scrums, and mauls. A number of studies have described the injury epidemiology of specific cohorts of rugby players. ${ }^{1-7}$ Typical patterns of injury have emerged from these studies. Overall, the findings suggest that injuries from rugby are distributed throughout the body. Most reported injuries have been to the soft tissues of the body (sprains, strains, and haematomas), and the tackle has generally been reported as the phase of play in which injuries most commonly occur. It appears that the rate of injury increases with higher levels of play, ${ }^{1248}$ perhaps because of the greater energy developed in the contact phases of the sport between larger and more powerful athletes. ${ }^{9}$ Specific injury types, such as spinal injuries, have also received attention; the mechanisms associated with these have been documented through case reports and case series studies. ${ }^{10}$

Various pieces of protective equipment are permitted within the laws of the game of rugby. ${ }^{11}$ These include padded headgear, shoulder pads, shin guards, and mouthguards. Little research on the effectiveness of the permitted equipment in preventing injuries has appeared in the scientific literature, although some appraisals of the various types of equipment have appeared.12-18 Garraway and colleagues ${ }^{4}$ speculated that protective equipment may lead to an increase in competitiveness in the contact phases of the sport, and a subsequent increase in injury rates, and called for a moratorium on the use of such equipment in competitive matches until the International Rugby Board (IRB) had assessed its effect on player morbidity.

At present, the wearing of mouthguards is permitted in rugby, but under the IRB laws of the game their use is not compulsory. In New Zealand a "domestic safety law variation" was introduced over the 1997-1998 seasons to require all players to wear mouthguards during matches. In 1997, mouthguard use became mandatory for all players at under 19 level and below, and in 1998 this was extended to players of all grades (levels of play). Although mouthguard use was mandated, there was no specific sanction available to the referee under the domestic safety law variation to ensure compliance with this law. A minor modification to the laws at the beginning of the 2003 season allowed referees greater powers in enforcing the laws, including the ability to send players from the field should they not be wearing a mouthguard in the prescribed fashion. These domestic safety law variations apply to all rugby played in New Zealand except for international competitions. Mouthguard use during team practices is optional, although it has been promoted through educational seminars. The primary purpose of this study was to document the effects of these rugby law changes in mouthguard use on rugby related dental injury claims made to ACC, the administrator of New Zealand's accident compensation scheme. A secondary purpose was to estimate the relative risk of dental injury claims for wearers and non-wearers of mouthguards.

\section{METHODS}

ACC is a public sector organisation charged with the administration of New Zealand's 24 hour, no fault accident compensation and rehabilitation scheme. ACC is required by statute to endeavour to prevent injuries, and compensate those in New Zealand who are injured. ACC insures all forms of personal injury including worker's compensation and

Abbreviations: IRB, International Rugby Board; NZRU, New Zealand Rugby Union; RIPP, Rugby Injury and Performance Project; RISP, Rugby Injury Surveillance Project 
compulsory third party insurance for motor vehicle injuries Injury claims are paid out over time in the form of income replacement, medical costs, and rehabilitation expenditure.

The criteria for the rugby related dental injury claims reported in this study were that the claim had a sport code of rugby union (ACC Sport Codes $=25$ or 79), an activity before the injury of recreation or sporting activity (ACC ap Code $=19$ ), and a forecast injury group of dental treatment (ACC fg $=15$ ). Hence dental injuries that occurred during rugby practices or matches could become claims. To allow comparisons in dental injury claim numbers from year to year to be made, the above criteria for claims acceptance were applied retrospectively to the ACC records. Information on rugby related dental injury claims was obtained from ACC over the period 1995-2003. The number of rugby players in New Zealand was obtained from New Zealand Rugby Union (NZRU) records.

Typical rates of mouthguard use were obtained from studies that surveyed mouthguard wearing rates before $(1993)^{19}$ and after $(2002 \text { and 2003 })^{820}$ the law changes took place. These studies used the same basic design for the collection of information, and the distribution of male players across the grades was similar. However, there were differences in the wording of the questions about mouthguard use. ${ }^{81920}$ Players were selected for the studies, and regular telephone interviews were used to enquire about exposure to rugby, injuries sustained, and protective equipment used.

The 1993 study involved a cohort of players from Dunedin, and was entitled the New Zealand Rugby Injury and Performance Project (RIPP). The methods ${ }^{21}$ and results ${ }^{1} 192223$ from RIPP have been reported. In summary, 345 players (258 male and 87 female) from a range of grades were contacted weekly by telephone throughout an entire rugby season. Use of mouthguards was reported for 327 players (240 male and 87 female) actively participating in rugby through the season. ${ }^{19}$ Active participation in rugby was defined as participation in at least one team practice or match during a particular week. The question relevant to mouthguard use asked in RIPP was: "Did you use any protective gear or strapping during team practice(s) or games last week? If yes, what did you wear? "Mouthguard" was one response category. Thus the rate reflected whether the player used a mouthguard during matches or team practices or both, but did not distinguish the rate of wearing during matches from that during practices.

Although the $2002^{20}$ and $2003^{8}$ Rugby Injury Surveillance Projects (RISPs) also used telephone interviews, there were a number of differences in design from the RIPP study. Firstly, players were selected from throughout New Zealand, and secondly the distribution of players by grade differed from that in RIPP; in the RISPs there were no female players.

The surveillance projects coincided with the modification in the powers available to the referee to mandate the use of mouthguards during matches noted above. The RISP studies used the NZRU player registration database to obtain representative samples of players aged 16 and over from various grades throughout the country. Different samples were obtained for each year. In 2002, 560 players were placed into two groups, one of which was contacted weekly, and the other was contacted fortnightly. The relevant question asked was "Did you wear any protective gear or strapping?" "Mouthguard" was one response category. This was asked for each game played and each practice attended. In 2003, information was collected from 774 players by weekly telephone interviews. The following question was asked: "Did you wear a mouthguard?" with the response categories "Yes/No/Did not answer". This was asked for each game played but not asked for practices.
For the purposes of estimating relative risks of dental claims for wearers compared with non-wearers of mouthguards, the female players in RIPP were excluded from the analysis. To estimate the relative risk of dental injury claims for non-wearers compared with wearers of mouthguards, we assumed that the rates of injury for wearers and non-wearers did not change between 1993 and 2003. We then solved the two simultaneous equations provided by the rate of claims for the two years to obtain the rates: (proportion of wearers) $\times$ (rate of injury for wearers) + (proportion of non-wearers) $\times$ (rate of injury for non-wearers $)=$ rate of claims. Confidence intervals for the relative risk were estimated by simulation: random error was added to the proportions consistent with the sample size from which they were derived (assuming a binomial sampling distribution), random error was added to the claim rates consistent with their totals (assuming a Poisson sampling distribution), and the equations were solved again; this process was repeated 400 times, and the confidence intervals were derived from the resulting values by assuming that the logarithm of the relative risk was normally distributed.

\section{RESULTS}

\section{Mouthguard use}

Over the period 1993-2003, the self reported rate of mouthguard use among male rugby players increased by $26 \% .{ }^{8}{ }^{19}$ Through the 1993 season, mouthguards were worn for $67 \%$ of player-weeks among the 240 men in a cohort of 327 Dunedin players from various grades who were enrolled in the RIPP.

In 2002, mouthguards were reported to be worn by players in the RISP in $85 \%$ of games and $38 \%$ of practices. In 2003 , they were reported to be worn in $93 \%$ of games. Mouthguard use during practices was assessed at the conclusion of the 2003 season. Most (59\%) players reported wearing mouthguards during practices at least sometimes. Of these players, $46 \%$ reported that they always wore mouthguards during practices involving contact.

\section{Player numbers}

Although accurate player numbers were not collected before 1998, the consensus view of NZRU staff was that they had remained reasonably constant throughout the mid-1990s. From 1998 onwards, numbers ranged between 120000 and 130000 (table 1). There was a recorded decrease in players of 8800 between 2000 and 2001 . This coincided with a change in the method of measuring player numbers. Before 2001, player numbers were estimated from a combination of registered players and number of teams enrolled in competitions. From 2001 onwards, numbers were taken solely from the NZRU player registration database. From 2001 to 2003 there was little change in player numbers.

\begin{tabular}{ll}
\hline $\begin{array}{l}\text { Table } 1 \\
\text { Zealand by year }\end{array}$ \\
\hline Year & Player numbers \\
\hline 1998 & 121900 \\
1999 & 129800 \\
2000 & 128700 \\
2001 & 119900 \\
2002 & 121600 \\
2003 & 120900 \\
\hline Source: New Zealand Rugby Union. Player numbers are \\
rounded to the nearest hundred.
\end{tabular}




\section{Dental injury claims}

Since the introduction of mandatory mouthguard wearing among New Zealand rugby players, there has been a $43 \%$ ( $90 \%$ confidence interval (CI) $39 \%$ to $46 \%$ ) reduction in rugby related dental injury claims to ACC (fig 1). In 1996, the year before mouthguards became compulsory for under 19 grades, 2690 rugby related dental injury claims were made to ACC. This represented a $2 \%$ increase in number of claims over the previous year. In 1997, this number dropped to 2316, a reduction of $14 \%$. The following year, there were 2136 claims, a further 8\% reduction. From 2002 to 2003, when referees were provided with additional sanctions to enforce the wearing of mouthguards, there was a reduction in claims of $5 \%$. The cumulative number of claims saved compared with the number of claims per year if claim numbers had remained constant from 1995 is 5839 . The average cost of a dental injury claim to ACC is \$321 NZD. The cumulative savings in claim costs compared with the cost per year if claim numbers had remained constant is \$1.87 million NZD. Using the methods and assumptions outlined above, the estimate for the relative risk of claims for wearers was 4.6 (90\% CI 3.8 to 5.6 ) times that of non-wearers.

Although claims could result from either matches or practices, mouthguard use is only compulsory during matches. The 2003 RISP study of rugby injuries in New Zealand ${ }^{8}$ indicated that injuries to the teeth and jaw made up only $1 \%$ of total injuries reported in both practices and matches. The rate of orofacial injuries was 0.7 per 1000 player-hours during matches, and 0.1 per 1000 player-hours during practices.

\section{DISCUSSION}

As with other studies using ecological methods, caution must be taken to ensure that the conclusions reached are not compromised by ecological fallacies, confounding, or bias. As far as possible, efforts have been made to account for other factors that may have contributed to the results observed. Although it is tempting to take the above findings at face value, issues that may have biased the findings must be addressed. Firstly, accurate records of player numbers were not available over the early period of the study. A large reduction in player numbers and/or in the typical amount of rugby exposure per player would obviously weaken the inference that the observed decrease in dental injury claims was associated with increased mouthguard use. Although the NZRU did not have all players recorded on a registration database throughout the study period, it unlikely that player numbers changed substantially over that period, and any

\section{Compulsory mouthguard use}

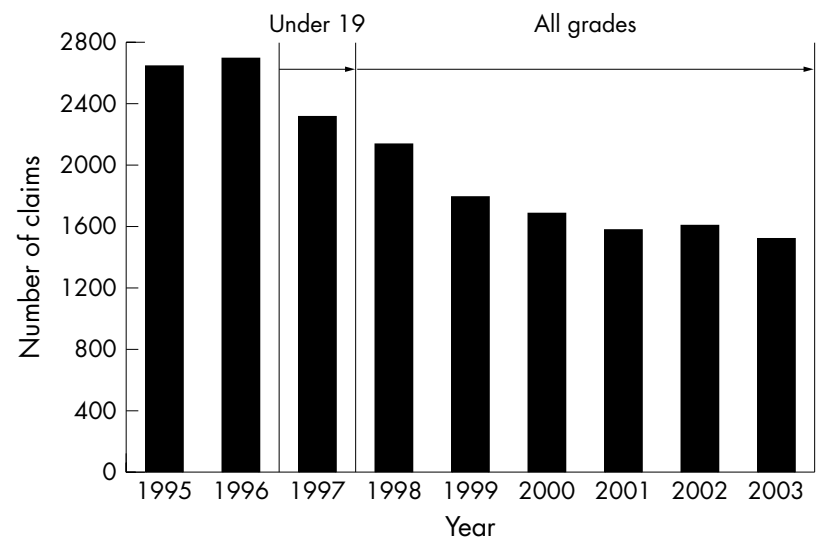

Figure 1 Rugby related dental injury claims in New Zealand. changes would certainly not have been of the order of a reduction of $40 \%$. Since 1998, variations in recorded numbers have been within $10 \%$, with the difference being primarily associated with a change in measurement methods as described above.

Secondly, the rate of mouthguard wearing in players throughout New Zealand in 1995 was assumed to be the same as that recorded for a sample of players from Dunedin in 1993. If the actual difference in wearing rates between the sample and the population over this time was large, the true relative rate of injuries to wearers and non-wearers would also be different from that estimated. A related problem is the fact that the wearing rates in practices and matches could not be distinguished in the RIPP study. The data collected on player wearing rates during practices at the end of the 2003 season indicate that these rates are substantially lower than for matches. In addition, mouthguard wearing rates were derived from studies that differed in terms of the questions used to investigate the rate of mouthguard wearing.

A fourth factor that may have had an effect is the type of mouthguard typically worn. If there were differences in the protection afforded by one type of mouthguard compared with another, and the proportions of players wearing the various types changed substantially, the relative risk of injury in the players who wore mouthguards may have changed over the period of the study. Finally, changes to the nature of the sport itself-for example, a large increase or decrease in the typical numbers of tackles per match-may have altered the risk of being injured. However, whether any such changes would have differentially modified the risk for non-wearers compared with wearers is not known.

To confidently assess the relation between mouthguard use and dental injuries would require much larger sample sizes than have been used in most of the previous studies on mouthguard use in rugby. ${ }^{24-31}$ A 1987 study by Blignaut and coworkers $^{25}$ that examined 321 players who participated in 555 player-matches concluded that there was no difference in oral injury rates between wearers and non-wearers of mouthguards. However, given the size of the sample and the frequency of oral injuries in rugby, the validity of such a conclusion must be questioned. A retrospective study in England examined self reported orofacial injuries in 114 senior players and 69 junior players. ${ }^{32}$ Among the senior players, 64 orofacial injuries were reported in the 54 players who did not typically wear mouthguards, compared with 18 injuries in the 60 players who did. This yields a relative rate of injury of 3.95 (90\% CI 2.5 to 6.1) for non-wearers versus wearers. Among the junior players, 23 orofacial injuries were reported by 24 non-wearers and 16 injuries by 45 nonwearers. The relative rate of injury among the junior players was 2.7 (90\% CI 1.6 to 4.6 ) for wearers versus non-wearers. Although the sample size in this study was small, the risk estimates are consistent with the relative risk calculated in the New Zealand situation.

The relative effectiveness of the various types of mouthguards available has also received little attention. Reviews of the role of mouthguards in preventing dental injuries in sports have suggested that dentist fitted mouthguards offer superior fit, comfort, and ability to breathe over the mouth fitted type. ${ }^{33}$ Chalmers ${ }^{12}$ recommended that mouthguards should be used in both practices and games and replaced often (about every two years). He stated that, although a number of factors would necessarily be taken into account in choosing a mouthguard (such as relative cost, age of the player, and the effectiveness of the different types), players in higher grades and in more vulnerable positions should invest in a dentist fitted mouthguard. However, despite the belief of dental experts that dentist fitted mouthguards offer superior protection because of less variability in thickness during the 


\section{What is already known on this topic}

There is a lack of epidemiological evidence about the effect of wearing mouthguards on dental injuries in contact sports.

process of construction and greater coverage of the teeth, ${ }^{33}$ there have been no studies with sufficient sample sizes and injury numbers to confirm a difference in rugby injury rates in practice. For example, in a study of 120 rugby players, 55 were provided with mouth fitted "boil and bite" type mouthguards, and 65 were provided with laboratory made mouthguards. Of the 98 players who were followed up at the end of the season, none had sustained damage to the teeth while wearing either type of mouthguard.$^{28}$ Further research examining the rates of claims among players wearing various types of mouthguards would help to clarify the relative effectiveness of the mouthguards currently available to players.

The logistics of further investigating the effects of wearing mouthguards, or comparing one type of mouthguard with another, would be less complicated in an experimental study than an observational study, especially with current wearing rates reported to be about $93 \%$ of player-weeks, but in the light of the findings presented, it is highly unlikely that ethical approval would be granted to assign players to a nonwearers group.

The changes to the laws of the sport in New Zealand have been supported by educational initiatives. Since 1996, all New Zealand coaches and referees of all grades of tackle rugby (typically under 9 and above) have been required to attend compulsory safety seminars. From 2001 onwards, these seminars have gone by the name "RugbySmart", and have focused on aspects of injury prevention such as technique, physical conditioning, injury management, and protective equipment (http://www.acc.co.nz/injury-prevention/safe-insport-and-recreation/sports-codes/rugby/rugbysmart 10points/). Mouthguard use as a means of preventing dental injuries has been promoted in these seminars and their accompanying resources.

A recent injury surveillance report indicates that, although the rates of both mouthguard wearing and orofacial injuries during practices are substantially lower than during matches, players spend more time in practices than in games. ${ }^{8}$ Although the wearing of mouthguards is optional during practices, we recommend that they should be worn during practices that involve contact.

The relative claim rate of 4.6 for non-wearers compared with wearers calculated above should be interpreted with some caution because the rates of mouthguard wearing were derived from studies that asked about mouthguard use in slightly different ways. In addition, there was a lack of certainty about player numbers in New Zealand and mouthguard wearing rates on a year by year basis. Even so, it is a step towards estimating the protective effect of mouthguards in rugby, and the large number of both players and claims allows greater confidence to be placed in the effect of mouthguards than was previously possible. The finding that mandating mouthguard use in New Zealand rugby has coincided with a $43 \%$ reduction in dental injury claims indicates that compelling players to wear mouthguards represents a simple and effective strategy to prevent dental injuries in rugby.

\section{CONCLUSION}

Despite the acknowledged weaknesses in ecological study designs, the findings presented provide evidence that compelling rugby players to wear mouthguards is a simple,
What this study adds

The introduction of compulsory wearing of mouthguards for rugby players in New Zealand has been associated with a $43 \%$ reduction in rugby related dental injury claims. The relative risk of making a dental injury claim for non-wearers was estimated to be 4.6 times that of wearers.

effective injury prevention strategy. On the basis of the New Zealand experience with compulsory mouthguard use and the commensurate decrease in dental injuries, we strongly endorse mouthguard use for rugby players at all levels in both match and contact practice situations.

\section{Authors' affiliations}

K L Quarrie, NZ Rugby Football Union, Research and Injury Prevention, Wellington, New Zealand

S M Gianotti, ACC, Auckland, New Zealand

D J Chalmers, Department of Preventive \& Social Medicine, University of Otago, Dunedin, New Zealand

K L Quarrie, W G Hopkins, New Zealand Institute for Sport and Recreation Research, Auckland University of Technology, Auckland, New Zealand

Competing interests: none declared

\section{REFERENCES}

1 Bird YN, Waller AE, Marshall SW, et al. The New Zealand Rugby Injury and Performance Project. V. Epidemiology of a season of rugby injury. $\mathrm{Br} J$ Sports Med 1998;32:319-25.

2 Durie RM, Munroe AD. A prospective survey of injuries in a New Zealand schoolboy rugby population. New Zealand Journal of Sports Medicine 2000;28:84-90.

3 Garraway M, Macleod D. Epidemiology of rugby football injuries. Lancet 1995:345:1485-7.

4 Garraway WM, Lee AJ, Hutton SJ, et al. Impact of professionalism on injuries in rugby union. Br J Sports Med 2000;34:348-51

5 Roux CE, Goedeke R, Visser GR, et al. The epidemiology of schoolboy rugby injuries. S Afr Med J 1987;71:307-13.

6 Bathgate A, Best JP, Craig G, et al. A prospective study of injuries to elite Australian rugby union players. Br J Sports Med 2002;36:265-9; discussion 269.

7 Targett SG. Injuries in professional Rugby Union. Clin J Sport Med 1998;8:280-5

8 Chalmers DJ, Gulliver P, Stephenson S. Routine surveillance of injuries and safety behaviour in rugby union football. Dunedin: Injury Prevention Research Unit, University of Otago, 2003.

9 McIntosh AS. Risk compensation, motivation, injuries, and biomechanics in competitive sport. Br J Sports Med 2005;39:2-3.

10 Quarrie KL, Cantu RC, Chalmers DJ. Rugby union injuries to the cervical spine and spinal cord. Sports Med 2002;32:633-53.

11 IRB. The Laws of the Game of Rugby Football. http://www.irb.com (accessed 27 May 2005).

12 Chalmers DJ. Mouthguards. Protection for the mouth in rugby union. Sports Med 1998;25:339-49.

13 Gerrard DF. The use of padding in rugby union. An overview. Sports Med 1998;25:329-32

14 Gerrard DF. External knee support in rugby union. Effectiveness of bracing and taping. Sports Med 1998;25:313-17.

15 Hume PA, Gerrard DF. Effectiveness of external ankle support. Bracing and taping in rugby union. Sports Med 1998;25:285-312.

16 Wilson BD. Protective headgear in rugby union. Sports Med 1998;25:333-7.

17 McIntosh AS, McCrory P. Effectiveness of headgear in a pilot study of under 15 rugby union football. Br J Sports Med 2001;35:167-9.

18 McIntosh A, McCrory P, Finch CF. Performance enhanced headgear: a scientific approach to the development of protective headgear. Br J Sports Med 2004;38:46-9.

19 Marshall SW, Waller AE, Loomis DP, et al. Use of protective equipment in a cohort of rugby players. Med Sci Sports Exerc 2001;33:2131-8.

20 Chalmers DJ, Gulliver P, Stephenson S. Routine surveillance of injuries and safety behaviour in rugby union football. Dunedin: Injury Prevention Research Unit, University of Otago, 2002.

21 Waller AE, Feehan M, Marshall SW, et al. The New Zealand Rugby Injury and Performance Project. I. Design and methodology of a prospective follow up study. Br J Sports Med 1994;28:223-8.

22 Gerrard DF, Waller AE, Bird YN. The New Zealand Rugby Injury and Performance Project. II. Previous injury experience of a rugby-playing cohort. Br J Sports Med 1994;28:229-33. 
23 Quarrie KL, Alsop JC, Waller AE, et al. The New Zealand rugby injury and performance project. VI. A prospective cohort study of risk factors for injury in rugby union football. Br J Sports Med 2001;35:157-66.

24 Kay EJ, Kakarla P, Macleod DA, et al. Oro-facial and dental injuries in club rugby union players. Br J Sports Med 1990;24:271-3.

25 Blignaut JB, Carstens IL, Lombard CJ. Injuries sustained in rugby by wearers and non-wearers of mouthguards. Br J Sports Med 1987;21:5-7.

26 Chapman PJ. The prevalence of orofacial injuries and use of mouthguards in Rugby Union. Aust Dent J 1985;30:364-7.

27 Upson N. Dental injuries and the attitudes of rugby players to mouthguards. Br J Sports Med 1982;16:241-4.

28 Upson N. Mouthguards, an evaluation of two types for Rugby players. Br J Sports Med 1985;19:89-92.
29 Chapman PJ. Orofacial injuries and mouthguards: a study of the 1984 Wallabies. Br J Sports Med 1985;19:93-5.

30 Chapman PJ, Nasser BP. Attitudes to mouthguards and prevalence of orofacial injuries in four teams competing at the second Rugby World Cup. Br J Sports Med 1993;27:197-9.

31 Chapman PJ, Nasser BP. Prevalence of orofacial injuries and use of mouthguards in high school Rugby Union. Aust Dent $J$ 1996;41:252-5.

32 Jennings $D C$. Injuries sustained by users and non-users of gum shields in local rugby union. Br J Sports Med 1990;24:159-65.

33 Newsome PR, Tran DC, Cooke MS. The role of the mouthguard in the prevention of sports-related dental injuries: a review. Int J Paediatr Dent 2001;11:396-404.

\section{Clinical Evidence-Call for contributors}

Clinical Evidence is a regularly updated evidence-based journal available worldwide both as a paper version and on the internet. Clinical Evidence needs to recruit a number of new contributors. Contributors are healthcare professionals or epidemiologists with experience in evidence-based medicine and the ability to write in a concise and structured way.

Areas for which we are currently seeking authors:

- Child health: nocturnal enuresis

- Eye disorders: bacterial conjunctivitis

- Male health: prostate cancer (metastatic)

- Women's health: pre-menstrual syndrome; pyelonephritis in non-pregnant women

However, we are always looking for others, so do not let this list discourage you.

Being a contributor involves:

- Selecting from a validated, screened search (performed by in-house Information Specialists) epidemiologically sound studies for inclusion.

- Documenting your decisions about which studies to include on an inclusion and exclusion form, which we keep on file.

- Writing the text to a highly structured template (about 1500-3000 words), using evidence from the final studies chosen, within 8-10 weeks of receiving the literature search.

- Working with Clinical Evidence editors to ensure that the final text meets epidemiological and style standards.

- Updating the text every six months using any new, sound evidence that becomes available. The Clinical Evidence in-house team will conduct the searches for contributors; your task is simply to filter out high quality studies and incorporate them in the existing text.

- To expand the topic to include a new question about once every 12-18 months.

If you would like to become a contributor for Clinical Evidence or require more information about what this involves please send your contact details and a copy of your CV, clearly stating the clinical area you are interested in, to Klara Brunnhuber (kbrunnhuber@ bmigroup.com).

\section{Call for peer reviewers}

Clinical Evidence also needs to recruit a number of new peer reviewers specifically with an interest in the clinical areas stated above, and also others related to general practice. Peer reviewers are healthcare professionals or epidemiologists with experience in evidence-based medicine. As a peer reviewer you would be asked for your views on the clinical relevance, validity, and accessibility of specific topics within the journal, and their usefulness to the intended audience (international generalists and healthcare professionals, possibly with limited statistical knowledge). Topics are usually 1500-3000 words in length and we would ask you to review between 2-5 topics per year. The peer review process takes place throughout the year, and our turnaround time for each review is ideally 10-14 days.

If you are interested in becoming a peer reviewer for Clinical Evidence, please complete the peer review questionnaire at www.clinicalevidence.com or contact Klara Brunnhuber (kbrunnhuber@bmigroup.com). 
pathology and its clinical correlation as well as on diagnosis, classification, reports, therapy, and secondly on rehabilitation, recovery, return to play, and prevention strategies of TBI in sport (i.e. amateur/professional boxing, ice hockey, soccer, American football, kick boxing kl, skiing, snowboarding, biking, climbing, etc.). There will be also report on the latest Second International Symposium on Concussion in November 2004 in Prague Czech Republic.

Further details: http://www.orthopaediesamedan.ch/mtbi.html

\section{International Congress on Sports Rehabilitation and Traumatology}

1-2 April 2006, Centro Congressi Lingotto, Torino, Italy

The congress will focus on the rehabilitation of winter and mountain sports injuries.

The deadline for poster presentation submissions is January 15th 2006.

Further details: Organising Secretary: Francesco Cervellati; Tel: +390516112568 Fax: +39051 6112567; Email: congressi@ isokinetic.com; Website: www.isokinetic.com

\section{UK Radiological Congress}

15-17 May 2006, NIA, ICC \& Austin Court, Birmingham, UK

UKRC 2006 will offer a conference programmes with speakers from the United States, Europe and Japan participating alongside internationally recognised UK speakers. The scientific programme will include a wide range of topics and some of the highlights include:

- Special focus sessions covering topics such as musculoskeletal radiology, breast imaging, nuclear medicine, neuroradiology, radiation cancer biology, radiotherapy, and MR imaging

- A one day course on the theory of ultrasound, which will cover the physics of ultrasound, ultrasound equipment, scanning techniques, image recording and reporting, and artefacts. The course will include practical demonstrations of ultrasound equipment in order to highlight many of the theoretical points

- The prominent themes of digital imaging and information technology, and their application to medical imaging and service delivery are included in digital imaging and service delivery programmes within the conference

Further details: Tel: + 44(0) 207307 1410/20; Fax: +44(0) 207307 1414; Email. conference @ukrc.org.uk / exhibition@ukrc.org.uk; Website. www.ukrc.org.uk

12th European Society of Sports Traumatology, Knee Surgery and Arthroscopy (ESSKA) 2000 Congress

24-27 May 2006, Innsbruck, Austria

Further details: Tel: +49 611 9771635; Website: www.esska2006.com

\section{4th European EISCSA Congress}

25-27 May 2006, Graz-Österreich, Germany Challenges in Exercise: Training and Therapy Further details: Tel: 0221 / 8011 00-0; Fax: 02 21 / 801100 29; Email: eiscsa2006@ comed-kongresse.de; Website www.comedkongresse.de

\section{Science and Racket Sports World Congress}

21-23 September 2006, Madrid, Spain

The congress will be held at the Spanish National Institute of Sport in Madrid, and in conjunction with the 8th International Badminton Federation (IBF) World Science Congress.

The congresses will take place during the World Badminton Championships, also in Madrid.

Further details: Dr David Cabello (dcabello@ ugr.es)

\section{AIPN 8th National Injury Prevention Conference}

27-29 September 2006, University of New South Wales, Sydney, Australia

Further details: http://www.aipn.com.au/ conference.html

\section{BASEM Conference 2006}

5-7 October 2006, Oxford, UK Further details: Email: BASEMinfo@aol.com; Website: www.basem.co.uk

\section{CORRECTION}

doi: 10.1136/bjsm.2004.016022corrl

K L Quarrie, S M Gianotti, D J Chalmers, et al. An evaluation of mouthguard requirements and dental injuries in New Zealand rugby union (Br J Sports Med 2005;39:650-4). A number of errors were spotted following publication of this article. The errors are as follows:

In the results section under the subheading "Dental injury claims" "wearers" and "non-wearers" are juxtaposed. The sentence should read:

Using the methods and assumptions outlined above, the estimate for the relative risk of claims for non-wearers was 4.6 (90\% CI 3.8 to 5.6) times that of wearers.

In the discussion section, the final two sentences contain errors. The penultimate sentence should read:

Among the junior players, 23 orofacial injuries were reported by 24 non-wearers and 16 injuries by 45 wearers.

In the final sentence of the fourth paragraph the words "wearers" and "nonwearers" are again in the wrong order. The last sentence of the fourth paragraph should read:

The relative rate of injury among the junior players was 2.7 (90\% CI 1.6 to 4.6 ) for nonwearers versus wearers.

The authors apologise for these errors. 